\title{
THE
}

\section{Post-implementation analysis: dependence and trust in VMI context}

Mehmet G. Yalcin

University of Rhode Island, mgyalcin@uri.edu

Koray Özpolat

University of Rhode Island, koray@uri.edu

Dara G. Schniedjans

University of Rhode Island, schniederjans@uri.edu

Follow this and additional works at: https://digitalcommons.uri.edu/cba_facpubs

The University of Rhode Island Faculty have made this article openly available. Please let us know how Open Access to this research benefits you.

This is a pre-publication author manuscript of the final, published article.

Terms of Use

This article is made available under the terms and conditions applicable towards Open Access Policy Articles, as set forth in our Terms of Use.

Citation/Publisher Attribution

Mehmet G. Yalcin, Koray Özpolat, Dara G. Schniederjans, (2018) "Post-implementation analysis: dependence and trust in VMI context", International Journal of Physical Distribution \& Logistics Management, Vol. 48 Issue: 7, pp.724-740, https://doi.org/10.1108/IJPDLM-09-2017-0294

Available at: https://doi.org/10.1108/IJPDLM-09-2017-0294 


\title{
Post-implementation analysis: dependence and trust in VMI context
}

\author{
Mehmet G. Yalcin* \\ Assistant Professor of Supply Chain Management \\ University of Rhode Island \\ College of Business \\ Kingston, RI 02881 \\ mgyalcin@uri.edu \\ 401-874-4247
}

Koray Özpolat

Associate Professor of Supply Chain Management

University of Rhode Island

College of Business

Kingston, RI 02881

koray@uri.edu

401-874-5750

Dara G. Schniederjans

Assistant Professor of Supply Chain Management

University of Rhode Island

College of Business

Kingston, RI 02881

schniederjans@uri.edu

401-874-4372

* Corresponding Author 


\title{
Post-implementation analysis: dependence and trust in VMI context
}

\begin{abstract}
Purpose - More than two decades long technological improvements in information sharing have not yet ensured a flawless execution of vendor managed inventory (VMI) and left interested parties wondering about the reasons of poor results. Although VMI is a collaborative tool, the relational factors in a VMI setting have not received enough attention due to challenges in obtaining relational buyer-supplier data in addition to extant focus on analytical approaches. In this paper, post-implementation relational factors are investigated in order to extract relevant insights. Design/methodology/approach - Accounting for the duration of the VMI relationship, we focus on two dimensions of VMI often ignored post-implementation: dependence of the buyer on the VMI-supplier and trust of the buyer in the VMI-supplier. Cross-sectional data were collected using a survey collected from distributors mostly in auto and electrical supply industries, which have their inventories managed by manufacturers through VMI arrangements. The sample was obtained from a leading third-party VMI-platform service provider that serves thousands of distributormanufacturer locations with billions of dollars in sales orders. Multiple Ordinary-Least-Squares (OLS) regression has been used to test the hypotheses.

Findings - This paper provides empirical support that in the post-implementation stage, longer VMI relationships are associated with higher distributor dependence on the manufacturer. In addition, too much dependence could actually hurt the distributor's trust in the manufacturer.

Practical implications - We propose that distributors maintain some of the purchasing and inventory management skills in house to limit their dependencies on the manufacturers. Manufacturers should also invest in trust-building activities, such as regular communications with distributors.

Originality/value - This is the first study providing empirical evidence on the (i) positive association between length of VMI relationship and buyer dependence on the supplier, and (ii) curvilinear dependence-trust link in a postimplementation VMI context.
\end{abstract}

Keywords Vendor managed inventory, VMI, Dependence, Trust, Collaborative relationships

Paper type Research 


\section{Introduction}

Adoption of vendor managed inventory (VMI) has steadily been on the rise in buyer-supplier relationships (Radzuan et al., 2015) and according to a survey conducted among executives where 73 percent of respondents were from Fortune 1000 companies, the VMI adoption rate reached 70 percent (E2open, 2015). E2open study also reports that while "the visibility into time-sensitive data continues to be a struggle", "there is a sustained demand for better inventory management collaboration” perhaps because the same study reports that 31 percent of the executives report below-average levels of VMI collaboration with their trading partners.

Recent studies provide comprehensive reviews of the extant VMI-related literature (Govindan, 2013; Akhbari et al., 2014) that explicate the benefits and how supply chain partners need to adjust the parameters within a VMI setting in order to ensure a successful relationship. While the literature classify and examine various VMI dimensions (Hong et al., 2016; Radzuan et al., 2015; Torres et al., 2014; Dong et al., 2014), a few incorporate trust as an influential factor and yet none look into the VMI relationship from a dependence perspective. This study investigates the dependence of the buyer on the supplier in a VMI relation with respect to trust that has to exist in a collaborative relationship between the upstream and downstream supply chain members (Ozer et al., 2011; Ayadi et al., 2013). Kauremaa et al. (2009) propose relationship patterns of VMI as basic, cooperative, and synchronized, suggesting that these layers depend on “dyadic intentions and contextual factors surrounding the given implementation.” Whether directed toward further collaboration or designed more as a transactional relationship, buyersupplier relations may evolve over time based on many factors. Yu et al. (2009) acknowledge the relational nature of the VMI and analyze it via evolutionary game theories by assuming the buyer 
as the dominant partner and leader of the supply chain. We consider a VMI situation under which neither the buying nor the selling company dominates the relationship.

Our decision scenario is inspired by the credible contracting branch that is explicated in the simple contracting schema proposed by Williamson (2002). Williamson suggests that incentive alignment plays a key role in establishing a credible contract between the buyer and the seller under private ordering situations in absence of a strict hierarchy (Williamson, 2002). In application of this scheme to a VMI context, two main components to VMI, information sharing and decision transfer (Dong et al., 2014), could be favoring the supplier due to increased dependence of the buyer on the supplier. However, the idea of aligning the incentives suggest that not only the VMI relation has to initiate from the state of an incentive equilibrium but also the equilibrium ought to be maintained throughout the course of the VMI relationship. In a collaborative setting such as VMI, it is demonstrated that while the network costs may be reduced, the realized benefits must be fairly distributed (Lehoux et al., 2011) which is often not the case (Yao et al., 2007). Therefore, it is possible that if there is an imbalance in the incentive structure (i.e. through a disturbance or perturbation of the incentive alignment) then either one or both of the parties in a buyer-supplier relationship may develop perceptions of contract violations (Özpolat and Dresner, 2018).

Since interdependencies between the firms vary in different settings, a VMI program should also be evaluated in light of relational factors which might extend the reach of the recent VMI frameworks proposed by scholars. In this empirical study, we examine the VMI program as a collaborative supply chain relationship from the buyer's dependence perspective. Using survey data collected from distributor-manufacturer relationships, we provide empirical evidence that longer VMI relationships are associated with higher distributor dependence on the manufacturer. While a moderate level of dependence is natural in collaborative VMI relationships, this paper also 
reveals that too much dependence could actually hurt the distributor trust in the manufacturer. Our findings contribute towards better understanding the mechanics of relational factors within the VMI relationship after the roll-out of the program.

The rest of this paper is organized as follows. Section two discusses the VMI method and relational factors. Section three evaluates the concept of dependence under a VMI setting. Section four describes the survey study that follows with results that yield from data analysis under section five. Section six presents the discussion of the results and concluding remarks along with limitations of the study. Further research suggestions are presented under section seven.

\section{Literature review}

VMI was initiated as a promising collaborative approach to managing inventories of the buyer by its supplier (Waller et al., 1999; Yu et al., 2009; Yang et al., 2012; Xu et al., 2016). To date, extant literature includes several studies related to the factors that affect the successful implementation of VMI. For instance, Yang et al. (2003) and Disney and Towill (2003) demonstrated VMI's effectiveness at mitigating the bullwhip effect and proposed a set of guidelines to aid managers for VMI implementation which includes the consideration of demand variability, inventory review interval, number of downstream firms, information availability and upstream firm’s flexibility. In order to identify the operational and strategic benefits of VMI and how these benefits are split between the upstream and downstream firms, Kauremaa et al. (2009) search and propose VMI implementations under three patterns, basic, cooperative, and synchronized. Reitner et al. (2012) developed a business process integration framework for the downstream firm to help firms act upon estimating the effects of VMI. Finally, Niranhan et al. (2011) describes how industry has created a practical approach which lists the preconditions for implementation of VMI under three 
headings; downstream firm (with stable growth, high transaction costs, good information and communication system, willingness to share information, and purchasing should not be a core competency), product (standardized, repeating, standard identification, low demand variance and demand is forecasted and stock levels are monitored), and upstream firm (supply chain trust/longterm relationships, advantages evident to both supplier and customer, key suppliers constitute a high percentage of purchase orders, suppliers are willing to cooperate, integrated information system) (Niranjan et al., 2011).

In these studies, however, the focus doesn't extend beyond the implementation stage. The exceptions are the studies by Yu et al. (2009) and Yao et al. (2012). Yu et al. (2009) explore VMI from a game theoretical perspective while Yao et al. (2012) investigate supply chain learning. Once VMI is implemented, the impact of VMI on relational factors between the downstream and upstream partners is still relatively unexplored. Specifically, the role of dependence is relatively under-explored in buyer-supplier relations research (Jean et al., 2012). Indisputably, ensuring a healthy implementation is targeted by scholars and industry professionals (Elvander et al., 2007; Govindan 2013); however, attention to post-implementation of VMI is of extreme value as suggested by extant research (Waller et al., 1999; Barratt and Oliveira, 2001; Dolci and Macada, 2014). This is due to investments required by the supply chain partners during implementation (Mishra, 2014) as well as the linkages between relational factors (i.e. interdependence, mutual trust, etc.) Supportively, it is suggested that "the actual research work lacks the roll-out sustainability of VMI, the step that will lead the new implementation towards expected benefits” (Govindan, 2013, p.3829). As such, this research model depicts the relationship between VMI and relational factors including dependence and trust. 


\section{VMI as a collaborative method}

Perona and Saccani (2004) classify the integration techniques in buyer supplier relationships and define a continuum where both VMI and CPFR need high relational commitment. Whipple and Russell (2007) examine the characteristics, requirements, benefits, and barriers to various collaborative relationships, propose a typology of collaborative approaches. Their typology includes three types and classify VMI as a Type I collaborative approach under the definition of collaborative transaction management which doesn't need as much social capital to run. Meanwhile, similar to Barratt (2004b), Whipple and Russell (2007) limit the expected “sustainable pay-off” for VMI under Type I relationships.

Achieving sustainable profits with the idea of creating sustainable competitive advantage by pursuing and establishing strategic collaborative relationships is very much in line with the rarity of CPFR relations. The exploratory study conducted by Whipple and Russell (2007) propose that the number of firms involved in Type I collaborative relationship, where they positioned the VMI, is greater than the other two levels (i.e. initial CPFR, event collaboration under Type II; advanced CPFR under Type III) whereas only a few firms operate under Type III level which requires more relational investment. By no means does the typology assert that relational investment is negligible for the VMI relations. Claassen et al. (2008) present in their findings that “buyer-perceived VMI success is impacted by the quality of the buyer-supplier relationship” among other tangible factors.

Angulo et al. (2004) summarize the potential benefits of a VMI relation based on the extant literature and most of these benefits can easily be realized in short term (Whipple and Russell, 2007) except the reduced costs through better utilization of the resources for production and transportation. This benefit requires the supplier to utilize the information received from the buyer 
via EDI and actually use it in production planning. According to Claassen et al. (2008), their results show that most VMI implementations fall short of realizing this benefit by the supplier not being able to fully control the pipeline. In turn, they adopt the term vendor managed replenishment (VMR) (e.g. Holweg et al., 2005) for implementations that are not integrated with the production. It is evident that in a VMI relationship, the supplier has both, more responsibilities and realizable benefits. On the other hand, Dong et al. (2013) find in their empirical study that following the VMI implementation, downstream firm's inventory is reduced; however, this inventory reduction may erode over time. Therefore, the "features that affect an organization's readiness for VMI" (Niranjan et al., 2011) need to be kept up to date following the initial implementation. If the expectations of the collaborating firms do not align in a VMI relation, VMI collaboration may create asymmetrical dependencies. In other words, the diminishing realizable benefits over the course of VMI relation may contribute to creation of dependence/power imbalance. Next, we discuss dependence in a VMI relation, which remains unexplored.

\section{Dependence}

Scholars investigated the role of dependence within inter-personal as well as inter-firm relationships in previous studies (Wells and Kipnis, 2001; Corsten and Felde, 2004). Andaleeb (1995) analyzes dependence, trust and control in manufacturer-distributor setting. In his study, he asserts that two important factors create perception of dependence: (1) The importance/criticality of the resources provided by the source firm, (2) The number of alternative sources available to the target firm. Thru criticality and lack of alternatives, dependence will lead to cooperation, trust will generate bonding forces and enhance cooperation and trust will minimize controls. Andaleeb (1995) also found that dependence is not related with controls and trust will minimize the strong influence stance. Hart and Saunders (1997) explore the relationships between EDI, power and trust 
within the context of buyer-seller dyad and study a case of EDI implementation in an innovative retail firm. In addition to revealing that coercive power deteriorates trust and persuasive power enhances trust, Hart and Saunders (1997) find that if the relative dependence is high, then the power of the resource-rich firm is higher to influence resource-dependent firms.

Studying the inter-organizational governance in marketing channels, Heide (1994) showed that while symmetric dependence promoted bilateral governance, unilateral dependence had negative effects. Specifically, for better interaction between the firms, both firms must be locked into the relationship, otherwise unilateral dependence would undermine bilateral governance. These results are similar to what Emerson (1962) had suggested when he analyzed power-dependence relations. According to Emerson (1962), power of party A(B) over party B(A) was linked to the dependence of party $\mathrm{B}(\mathrm{A})$ to party $\mathrm{A}(\mathrm{B})$. Under balanced or equilibrium situations, dependence levels would be equal which would lead to powers being equal. This resembles a collaborative relationship where both parties depend on each other equally and there is a power balance or equilibrium. However, in an unbalanced situation where there is dependence imbalance (dependence of A on B is not equal to dependence of B on A), Emerson (1962) suggests that there will also be power imbalance and the collaboration between the parties will suffer and the balance will be sought in the power equation. Eventually balancing operations will occur one of three ways: (i) Withdrawal of the less powerful (more dependent) party, or (ii) coalition of the less powerful parties, or (iii) the action of status upgrade (give more power) by the more powerful to the less powerful. Similarly, Frazier (1999) discusses the high and symmetric interdependence between firms in a dyadic channel relationship. He suggests that in a low interdependence situation, the amount of attention and support between the firms is also low. He highlights that for further and/or stronger collaboration between firms, power should not be evaluated as a negative phenomenon but instead 
high joint power should be nurtured. On the other hand, Ireland and Webb (2007) conclude that high levels of trust and power are not necessary in all relationships and they suggest that firms should appropriately balance trust and power.

\section{Dependence in distributor manufacturer VMI setting}

In a distributor-manufacturer VMI setting, it is expected that lack of joint decision making will cause the distributor to rely on manufacturer's actions. Moreover, because the distributor will eventually lose its expertise of placing orders and inventory management, dependence will most likely increase.

Dong et al. (2014) point to the decision transfer from the buyer to seller as VMI's difference from other information sharing collaborative supply chain programs. Their study splits the VMI program into two components, namely, information sharing and decision transfer and focuses on the benefits of decision transfer. Considering the findings of Dong et al. (2014) in conjunction with that of Ketchen and Hult (2007) provide further understanding the relational dynamics of VMI: (i) The initiation of a VMI relationship can be explained by the resource dependence theory and VMI is a collaborative supply chain method, (ii) Once the VMI program is initiated, the focus should be to invest in social capital between the buyer and the seller. Shared goals, values and experiences of the VMI program should constantly be emphasized and these goals, values and experiences should be updated based on the needs of the firms.

In VMI, distributors depend on manufacturers to make decisions that are mutually beneficial based on information shared. Until improvements and subsequent benefits in inventory management are fully realized, the distributors continue to share information unilaterally within a VMI relation, which suggests that dependence of the distributor on the manufacturer will increase. 
Also considering loss of distributors' inventory management and ordering skills, we hypothesize that:

H1: Longer VMI relationships are associated with higher distributor dependence on the manufacturer.

Next, we develop our second hypothesis on the relationship between dependence and trust. Trust plays a key role in buyer-supplier relationships. Liker and Choi (2004) report an American supplier's dissatisfaction with Ford, GM and Chrysler as follows: "The Big Three [U.S. automakers] set annual cost-reduction targets [for the parts they purchase]. To realize those targets, they'll do anything. They've unleashed a reign of terror, and it gets worse every year. You can't trust anyone in those companies.” Hence it is not surprising that US auto makers have consistently ranked below Toyota and Honda in many measures including reliability, trustworthiness and profitability. In a VMI context, the role of trust is critical both at the start and for the continuity of the relationship. The upstream and downstream firms enter into a VMI program in order to reduce the transaction costs and improve inventory performance. However, at the same time, due to some initial investment on EDI systems, there has to be a certain level of trust during the inception of the VMI program. It takes about two years for VMI to fully start working (Mishra, 2014) and during this time, VMI program is improved through social exchanges. These social exchanges increase downstream firm's trust in the upstream firm along with the increased dependency.

Once VMI program is fully established and the inventory replenishment is integrated into the manufacturer's production schedule, it is assumed that there will be fewer issues with the replenishment. However, this will reduce the communication between the firms to even lower 
levels. Bunduchi (2007, pp.619-table 2) suggests that "online content and commerce functionalities reduce personal trust by replacing face to face communication and personal trust”. In essence, VMI program may not sustain business relationships with minimal amounts or in absence of personal interaction between the employees. Furthermore, since the manufacturer is the sole decision maker and acting as the distributor's agent, lack of communication at advanced stages of a VMI program may cause agents acting for their own interest and perhaps putting the principal's interest on the back seat. In their study, Villena et al. (2011) found that "either too little or too much social capital can hurt performance.” This study confirms that building social capital in a collaborative buyer supplier relationship positively affects buyer performance, but that if taken to an extreme, it can reduce the buyer's ability to be objective and make effective decisions as well as increase the supplier's opportunistic behavior.”

Foreseeing this reliance, the manufacturer should be trustworthy enough for the distributor and then the distributor would have to have trust to the manufacturer. Once the VMI relation is well under way and the initial low-hanging performance improvements have been achieved, any problems that may have an effect on performance of distributor will be interpreted as violation against the VMI collaboration. These violations will pave the way to erosion of trust over time.

Building on our first hypothesis, high levels of dependence is not desired unless balanced with trust and long VMI relationships could increase the likelihood of an adversely impactful imbalance due to higher levels of dependence. Based on preliminary research, exaggerated resource dependence is found to have an adverse effect on trust (Brinkhoff et al., 2015) and trust is best nurtured in mutual dependency conditions (Emerson, 1962). However, unlike Brinkhoff et al. (2015), we contend that VMI relationship should be evaluated similar to the approach in the evolutionary game theory (Torres et al., 2014) because the relational factors (i.e. dependence and 
trust) evolve as the VMI initiative matures over time. In other words, as long as dependence and trust levels are nurtured and balanced appropriately through social exchanges, moderate levels of dependence may be sustainable. Therefore, distributor dependence on the manufacturer should exist for VMI commitment; however, possessing too much dependence during critical decision making moments may increase the likelihood of considerably deteriorating trust due to power imbalance, which can be hypothesized as:

H2: There is an inverted curvilinear (inverse-U) relationship between a distributor's dependence on the manufacturer and trust in the manufacturer

\section{Methodology}

In this empirical research, the unit of analysis is the distributor-manufacturer VMI relationship. Within this relationship, the distributors share the item-level point-of-sales data as well as the inventory levels with their manufacturers thru EDI (electronic data interchange). In turn, the manufacturers manage and replenish the inventories at the distributors (no consignment). Our survey study explores the multiple buyer and multiple supplier setting.

A third party VMI service provider, that focuses on auto parts, electrical supplies, consumer goods and plumbing products, was contacted in order to reach out to the survey respondents at the distributors. This electronic data interchange (EDI) provider connects the systems of thousands of manufacturers, distributors and retailers and enables information sharing among them for millions of SKUs under which the operations amount to billions of dollars in sales orders. Utilizing a survey study on 200 distributors where the inventories are managed by the manufacturers under a VMI setting, the cross-sectional data were collected from the respondents who were, per Kumar et al. (1993) recommendation, senior level positions supervising the daily 
VMI relationships. The response rate of the survey was 33.3 percent. While all of the distributors were from North America, all but four percent from Canada were located in U.S. These distributors were all independent entities that owned the inventories at their facilities. Following the common approach that asks participants to refer to a major or significant supply chain partner in answering survey questions (Hill et al., 2009; Liu et al., 2012), the respondents were asked to answer survey questions by referencing their largest VMI relation if they had multiple VMI relations.

The EDI 852 (Product Activity Data document) accommodation that is provided by the third party VMI service provider enables the distributors to share item-level point-of-sales data and inventory levels daily with their manufacturers. The manufacturers make replenishment decisions based on these data. The accommodation by the service provider is limited at the technical level and doesn't extend into making inventory level or order decisions. However, the service provider not only ensures that the flawless communication between the partners but also promotes the sharing of best practices by arranging annual conferences.

The draft of survey was reviewed for content, clarity, flow and coherence by three logistics and supply chain researchers. Additionally two industry professionals pre-tested and enhanced the survey. The final survey had 32 question which is fewer than the suggested threshold by Dillman (1978) for a good response rate. Following a pre-notification e-mail a week ahead, the link to online survey was e-mailed to the contacts at each distributor with a couple of reminders for two consecutive Tuesdays in the late mornings which are believed to be less busy times in general than other days. To encourage interest in the survey, \$2 donation was offered to be made to National Wildlife Federation on behalf of each respondent if they completed the survey. At the end, there were 38 responses in the first, 17 responses in the second and 2 responses in the third batch after each of the three reminders. 
In the survey, besides respondent's position in the distributor, their length of employment with the firm was also questioned which revealed that only three percent of the respondents had held their positions for less than a year. This provided a source of confidence in our survey in terms of levels of competency and knowledge of the respondents to effectively complete the survey. On the other hand, profiles of the distributors revealed that the distributors vary in size and come from electrical supplies, auto parts, plumbing supplies, and consumer goods industries.

We contacted 200 distributors and managed to reach 162 of them, where 29 email addresses bounced back, 5 opted out of survey and 4 mentioned that they no more used VMI. The 57 survey responses out of 162 distributors contained three responses that were deemed incomplete and therefore omitted from the study resulting in 54 usable responses which yielded a 33.3 percent response rate. Testing for non-response bias, we compared the early and late responses per Armsrong and Overton (1977) by considering the late responses as a proxy for non-responses, and observed that the differences between early and late responses for key variables (i.e. trust, dependence, length of VMI) were not significant. Common method bias was also controlled to ensure the validity of the survey. Designing the survey, propensity-to-trust variable was included to control for potential respondent bias per Podsakoff et al. (2003, p.889). Additionally, reversecoded questions were included in some of the components to minimize response pattern biases. Following Kaiser's eigenvalue greater-than-one criterion, the items and the components were double checked via factor analysis methods to confirm the reliability of underlying dimensions and verified that explained variance by the components is more than 50 percent.

\section{Items and components}


The survey questions, each corresponding to an item for an underlying dimension, were adopted from prior studies but have been modified with the feedback received from research colleagues and industry professionals to fit into the VMI setting. Most of the questions utilized a five-point Likert scale while there were also forced-choice questions inquiring a yes/no answer (see Table IV in Appendix).

The primary dependent variable, dependence, represented distributor's dependence on its largest VMI manufacturer. As a latent variable, dependence was composed of four ordinal measurement items via the following questions: Approximately what percent of your purchases (\$ value) is from this supplier? Replenishment of what percent of the products you purchase from this supplier is done through VMI? Is this supplier important to our firm? Approximately how many other suppliers are available in the supply market for the product(s) you purchase from this supplier? Observing the dependence levels for different lengths of VMI relationship, the VMI relations that are less than 2 years have a mean dependence level of 3.03 while those that are longer than 6 years have a mean dependence of 3.43 .

The other focal dependent variable, trust, encompassed the distributor's trust in its largest VMI manufacturer. Three dimensions of this latent trust variable (benevolence, integrity and ability) were measured with ordinal item scales for each dimension based on prior literature (Mayer et al., 1995).

Length of VMI relationship was a key independent variable where the length was simply requested from the respondent in years as an ordinal unit of measure. The control variables included the latent "propensity to trust" variable, length of business relationship with the subject manufacturer, size of the distributor, performance measured as ordinal variables and the binary 
dummy variables for the auto and electrical industries with other industries referenced as the base. The industry frequency and distributor size data are presented in Table Ia and Table Ib respectively.

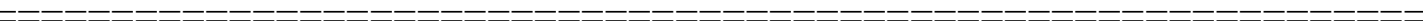

INSERT TABLES Ia and Ib APPROXIMATELY HERE

Table IIa provide descriptive statistics for the above variables. Evaluating these statistics along with the scatterplots, no major concerns are observed with respect to normality, linearity and homoscedasticity assumptions. Additionally, the correlations between the variables were investigated for potential multicollinearity as presented in Table IIb. All values were below 0.7 and the highest correlation was between ptt and trust which was expected as ptt was included to control for the potential respondent bias. We also stepwise dropped the moderately correlated variables and re-ran the regressions; which did not result in any significant change in coefficients magnitude or significance.

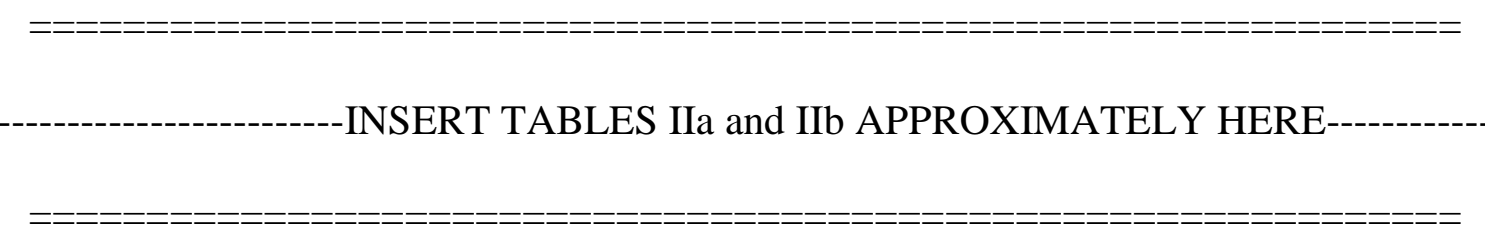

\section{Analysis and results}

In this study, ordinary least squares regression is employed. There are 3 models; one for first hypothesis and two for the second hypothesis where the models are constructed as follows:

\section{H1 Model 1:}

Dependence $=\alpha+\beta_{1}$ Length of VMI relationship $+\beta_{2}$ Size $+\beta_{3,4}$ Industry dummies $+\beta_{5}$ Industry VMI use $+\beta_{6}$ Performance $+\varepsilon$

\section{H2 Model 2:}


Trust $=\alpha+\beta_{1}$ Length of business relationship $+\beta_{2}$ Size $+\beta_{3}$ Dependence $+\beta_{4}$ Propensity to trust $+\beta_{5,6}$ Industry dummies $+\beta_{7}$ Industry VMI use $+\beta_{8}$ Performance $+\varepsilon$

\section{H2 Model 3:}

Trust $=\alpha+\beta_{1}$ Length of business relationship $+\beta_{2}$ Size $+\beta_{3}$ Dependence $+\beta_{4}$ Dependence $^{2}+\beta_{5}$ Propensity to trust $+\beta_{6,7}$ Industry dummies $+\beta_{8}$ Industry VMI use $+\beta_{9}$ Performance $+\varepsilon$

The results of the OLS regression are presented on Table III below. In Model 1, the dependent variable "Dependence" is regressed on length of VMI along where control variables of industry VMI use, performance, size of distributor, auto and electrical industry dummies were employed. The micro-level results revealed that length of VMI as a significant predictor of dependence levels with the coefficient of $0.17^{*}$. Industry VMI use and performance variables were also significant.

-INSERT TABLE III APPROXIMATELY HERE

The first model explained about 31 percent of the variance in dependence. This provided support for the first hypothesis that longer VMI relationships are associated with higher distributor dependence on the manufacturer (see Figure Ia). Based on this, for a distributor with a mean dependence level of 3.26 (un-normalized $=3.26 * 4=13.04$ ), ceteris paribus, a year increase in the length of VMI relationship results in a 1.30 percent $(0.17 / 13.04)$ increase in distributor's dependence on its VMI manufacturer.

The second and third models were developed for the second hypothesis where the dependent variable was set as "trust” along with the primary independent variable, “dependence”. In the 
third model, the quadratic square term for dependence was added to the second model in an effort to search for an inverse $U$ relationship between trust and dependence levels of the distributor for its manufacturer. In the second model, in absence of the square dependence term, the length of business relation $\left(-0.41^{* *}\right)$ and the propensity to trust $\left(0.67^{* * *}\right)$ were significant while the linear dependence variable was not significant. Explained variance for this model was 33 percent. The third model did not result in much of a change in the coefficients of the control variables. In an effort to search for both, improving the model and establishing an inverse $\mathrm{U}$ relation between trust and dependence, the square term for dependence was added where it was observed to be significant with a negative sign $\left(-0.11^{*}\right)$. While the square term was significant, it also resulted in revealing the linear term as positive and significant (2.85*). These two values established a curvilinear relation that is reminiscent of an inverse $\mathrm{U}$ relation, which is represented in below graph (with un-normalized values) and the values shown to be within the range of survey data (see Figure Ib). Finally, the third model revealed added improvement to the overall fit with an explained variance of 38 percent.

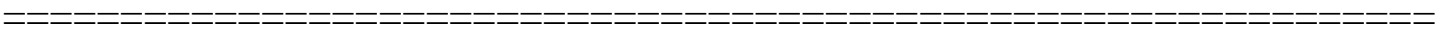

-INSERT FIGURE Ia \& b APPROXIMATELY HERE-

\section{Discussion}

Utilizing survey data collected from distributors that have their inventories managed by manufacturers through VMI arrangements, we provide empirical evidence that longer VMI relationships are associated with increased distributor dependence on the manufacturer. Moreover, 
we identify an inverted $U$ shape relationship between distributors' dependence on the manufacturers and distributors' trust in the manufacturers.

We make two contributions to the academic literature. This is the first paper empirically demonstrating that use of VMI creates dependencies on the distributor (buyer). As the manufacturer (supplier) takes over the replenishment process, the distributor loses critical purchasing and inventory management skills which increases dependency on the supplier. The increased levels of dependence could be exacerbated by lack of much needed in-house skills for analysis of VMI performance, as well as ensuring competitive contracting on future projects. Aligned with Heide (1994) findings that unilateral dependence has negative effects on bilateral governance, our findings establish a link between over-dependence on manufacturers and lower trust levels. While increased unilateral dependence may not necessarily cause direct harm to the relationship, we find that it could pose negative implications on other relational factors - such as trust. Hence our second contribution is to the organizational literature providing empirical evidence on the curvilinear dependence-trust link in collaborative supply chain relationships. Previously, Villena et al. (2011) showed that in buyer-supplier relationships, too much social capital generated by highly collaborative relationships, could decrease a buyer's objectivity and increase a supplier's opportunistic behavior - thus hurting supply chain performance. We extend their findings such that highly collaborative relationships could have inter-organizational trust problems caused by over-dependency as the relationship matures.

This study also offers a few managerial implications. As distributor's trust on the manufacturer will erode beyond certain levels of dependence of distributor on the manufacturer, we suggest that distributors keep some purchasing and inventory management expertise in house to prevent over-dependence and also allow them an optional exit. Joint decision making is rare in 
VMI relationships and realizable benefits are limited relative to more advanced CPFR relations (Whipple and Russell, 2007). Distributors depend on manufacturers to make decisions that are beneficial for both parties based on the information that is shared electronically. VMI partners experience changes and witness improvements until all issues are resolved and VMI benefits are fully realized. In other words, once the easily achievable benefits are realized by both parties, the manufacturer's motive might concentrate more on maintaining the integrated production planning while the distributor stops seeing further improvements. A possible reason could be that the manufacturer may not be able to accommodate its downstream VMI partner on the replenishment priority list. This behavior is reminiscent of the opportunistic approach of the firm with the transaction cost economics mindset. Perhaps not intentionally, but eventually, when the manufacturer focuses on its own benefits in absence of the additional distributor benefits (which are limited in VMI), the VMI relationship seems to dislodge from the initial collaboration commitment. The main reason for this is the underlying concept of allowing the manufacturer to take over the management of the distributor's inventory. Lack of control might also instill the sense of uncertainty and then increased perception of dependence. More importantly, as the distributor's additional benefits stagnate, further collaboration halts.

Michalski et al. (2013) focus on the notion of asymmetries changing the behaviors of participants in collaborative arrangements in supply chain management and find that asymmetry influences various relationships disparately through its multi-faceted presence. Along with upward trends in volumes of replenishment, reduction in the number of alternative suppliers, and increase in criticality of the particular supplies, VMI programs increase dependence levels. Unless proper social capital investments are made, it is expected that trust towards the supplier will also suffer. In their study, where the upstream firm is dependent to the downstream firm, Yu et al. (2009) 
employed a game theoretical model and found that in early stages of a VMI implementation, upstream firm has fewer benefits than the downstream firm and may even experience profit loss trying to maintain the relation but eventually, increase in transaction quantity between the firms result in increased profits for both parties. This ought to be considered because due to its limited nature, VMI partners may not expect further benefits in the horizon. Ultimately, unbalanced resource dependence is created when the distributor is left vulnerable to manufacturer's actions. Furthermore, dependence imbalance could hurt the outcomes of the VMI relationship which may alternatively be interpreted as deterioration of trust (Brinkoff et al., 2014). Essentially, the buyersupplier relation will evolve toward either a traditional supply chain or VMI supply chain (Yu et al., 2009).

\section{Conclusion}

Handfield (2013) recommends manufacturers to be careful in launching VMI relationships, "Contrary to what many people think, companies like Toyota and Honda have moved away from VMI and simply chose to co-locate suppliers as close as possible to their facilities.” Although literature points to multiple VMI failures, the world's largest cloud based VMI service provider Datalliance recently reported more than twenty years of consecutive growth (Nasdaq, 2017). E2open, a cloud based supply chain software company, is pursuing further opportunities based on the survey results demonstrating only 33 percent of the executives feel that inventory levels reflect optimized cost and service levels (E2open, 2015). While still believing in the potential of VMI, we propose that post-implementation stage merits more attention to dependence and trust. Since it is possible that the unilateral dependence may create power imbalance and hurt the relationship through eroding trust, the distributors should limit dependence levels on their manufacturers to 
certain upper boundaries before the rollout of the VMI relation. Once under way, the expectations from VMI collaborations should be adjusted accordingly and sufficient relational investments ought to be allocated for advancing the collaboration beyond VMI. Other considerations can be listed but not limited to working on back-up plans such as dual sourcing, and also evaluating the efficacy of keeping certain critical purchasing and inventory skills in-house in lieu of targeting extended cost savings.

The above study's primary limitation is the sample size which might explain the small effect size in the analysis. On the other hand, limited scope of the industries may also have an impact on the generalizability of the findings. In relation to scope of industries, the manufacturer vs. distributor context adds another constraint. Retailer vs. distributor and manufacturer vs. raw materials supplier settings reside as potential avenues for explore. While single VMI service provider may have caused reduction in the survey response pool, we are also aware that excluding those VMI relations that may have failed earlier could introduce relationship survival bias and its effects would be unknown. The findings do not infer causality due to the nature of the crosssectional data. Additionally, this study only assesses the relational variables from the distributor. Knowing that the relational factors such as dependence and trust are mutual, a follow-up study could be conducted by including the survey data for corresponding manufacturers. Single in depth case study of a VMI relation could reveal many detailed insights and multiple case studies within and across industries as well as buyer-supplier contexts would be highly beneficial in developing the theory in VMI relations. In an ideal setting, longitudinal studies that capture both sides of the VMI relationships would be most helpful in observing the dependence-trust link over time.

\section{Appendix}




\section{References}

Akhbari, M., Zare Mehrjerdi, Y., Khademi Zare, H. and Makui, A. (2014), "VMI-type supply chains: A brief review”, Journal of Optimization in Industrial Engineering, Vol. 7 No. 14, pp. 7587.

Andaleeb, S. S. (1995), "Dependence relations and the moderating role of trust: Implications for behavioral intentions in marketing channels”, International Journal of Research in Marketing, Vol. 12 No. 2, p. 157.

Angulo, A., Nachtmann, H. and Waller, M. A. (2004), "Supply chain information sharing in a vendor managed inventory partnership”, Journal of Business Logistics, Vol. 25 No. 1, pp. 101120.

Armstrong, J. S. and Overton, T. S. (1977), "Estimating nonresponse bias in mail surveys", Journal of Marketing Research, Vol. 14 No. 8, pp. 396-402.

Ayadi, O., Cheikhrouhou, N. and Masmoudi, F. (2013), “A decision support system assessing the trust level in supply chains based on information sharing dimensions", Computers \& Industrial Engineering, Vol. 66 No. 2, pp. 242-257.

Barratt, M. (2004a), “Understanding the meaning of collaboration in the supply chain”, Supply Chain Management: An International Journal, Vol. 9 No. 1, pp. 30-42.

Barratt, M. (2004b), “Unveiling enablers and inhibitors of collaborative planning”, International Journal of Logistics Management, Vol. 15 No. 1, pp. 73-90.

Barratt, M. and Oliveira, A. (2001), "Exploring the experiences of collaborative planning initiatives”, International Journal of Physical Distribution \& Logistics Management, Vol. 31 No. 4, pp. 266-289.

Brinkhoff, A., Özer, Ö. and Sargut, G. (2015), “All you need is trust? An examination of interorganizational supply chain projects”, Production and Operations Management, Vol. 24 No. 1, pp. 181-200.

Bunduchi, R. (2007), “An empirical investigation of the role of trust and power in shaping the use of electronic markets", in Li, F. (Ed.), Social Implications and Challenges of E-business, Information Science Reference, Hershey, PA, pp. 159-172. 
Claassen, M. J. T., van Weele, A.,J. and van Raaij, E.,M. (2008), "Performance outcomes and success factors of vendor managed inventory (VMI)", Supply Chain Management: An International Journal, Vol. 13 No. 6, pp. 406-414.

Cooke, J. A. (1998), “VMI: Very mixed impact?” Logistics Management and Distribution Report, Vol. 37 No. 12, pp. 51-53.

Corsten, D. and Felde, J. (2005), "Exploring the performance effects of key-supplier collaboration”, International Journal of Physical Distribution \& Logistics Management, Vol. 35 No. 6, pp. 445-461.

Daugherty, P. J., Myers, M. B. and Autry, C. W. (1999), “Automatic replenishment programs: An empirical examination”, Journal of Business Logistics, Vol. 20 No. 2, pp. 63-82.

Dillman, D. A. (1978), Mail and Telephone Surveys (Vol. 3), Wiley Interscience, New York, NY.

Disney, S. M. and Towill, D. R. (2003), “The effect of vendor managed inventory (VMI) dynamics on the Bullwhip Effect in supply chains”, International Journal of Production Economics, Vol. 85 No. 2, pp. 199-215.

Dolci, P. C. and Maçada, A. C. G. (2014), "Information technology investments and supply chain governance”, Revista De Administração Contemporânea, Vol. 18 No. 2, pp. 217-235.

Dong, Y., Dresner, M., and Yao, Y. (2014), “Beyond information sharing: An empirical analysis of vendor-managed inventory", Production and Operations Management, Vol. 23 No. 5, pp. 817828.

E2open (2015), “Industry research shows legacy systems fail to deliver on vendor managed inventory”, available at: https://www.e2open.com/news/industry-researchshows-legacy-systems-fail-to-deliver-on-vendor-managed-inventory (accessed 06 February 2018).

Elvander, M. S., Sarpola, S. and Mattsson, S. (2007), "Framework for characterizing the design of VMI systems”, International Journal of Physical Distribution \& Logistics Management, Vol. 37 No. 10, pp. 782 - 798.

Emerson, R. M. (1962), “Power-dependence relations”, American Sociological Review, Vol. 27 No. 1, pp. 31-41.

Frazier, G. L. (1999), “Organizing and managing channels of distribution”, Academy of Marketing Science Journal, Vol. 27 No. 2, pp. 226-240.

Govindan, K. (2013), “Vendor-managed inventory: A review based on dimensions”, International Journal of Production Research, Vol. 51 No. 13, pp. 3808-3819. 
Handfield, R. (2013), "Vendor Managed Inventory? Think twice and consider the risks", available at: https://scm.ncsu.edu/blog/2013/08/28/vendor-managed-inventory-think-twice-andconsider-the-risks/\#comments (accessed 21 September 2017).

Hart, P. and Saunders, C. (1997), "Power and trust: Critical factors in the adoption and use of electronic data interchange”, Organization Science, Vol. 8 No. 1, pp. 23-42.

Heide, J. B. (1994), "Interorganizational governance in marketing channels", Journal of Marketing, Vol. 58 No. 1, pp. 71-85.

Hill, J. A., Eckerd, S., Wilson, D. and Greer, B. (2009), "The effect of unethical behavior on trust in a buyer-supplier relationship: The mediating role of psychological contract violation”, Journal of Operations Management, Vol. 27 No. 4, pp. 281-293.

Holweg, M., Disney, S., Holmstrom, J. and Smaros, J. (2005), "Supply chain collaboration: Making sense of the strategy continuum”, European Management Journal, Vol. 23 No. 2, pp. 170181.

Hong, X., Chunyuan, W., Xu, L. and Diabat, A. (2016), "Multiple-vendor, multiple-retailer based vendor-managed inventory”, Annals of Operations Research, Vol. 238 Nos. 1-2, pp. 277-297.

Ireland, R. and Bruce, R. (2000), "CPFR: only the beginning of collaboration", Supply Chain Management Review, Vol. 4 No. 4, pp. 80-88.

Ireland, R. D. and Webb, J. W. (2007), "A multi-theoretic perspective on trust and power in strategic supply chains”, Journal of Operations Management, Vol. 25 No. 2, pp. 482-497.

Jean, R. J., Kim, D. and Sinkovics, R. R. (2012), "Drivers and performance outcomes of supplier innovation generation in customer-supplier relationships: The role of power-dependence", Decision Sciences, Vol. 43 No. 6, pp. 1003-1038.

Kauremaa, J., Småros, J. and Holmström, J. (2009), "Patterns of vendor-managed inventory: Findings from a multiple-case study", International Journal of Operations \& Production Management, Vol. 29 No. 11, pp. 1109-1139.

Ketchen, D. J. Jr. and Hult, G. T. (2007), "Bridging organization theory and supply chain management: The case of best value supply chains", Journal of Operations Management, Vol. 25 No. 2, pp. 573-580.

Kumar, N., Stern, L. W. and Anderson, J. C. (1993), "Conducting interorganizational research using key informants”, Academy of Management Journal, Vol. 36 No. 6, pp. 1633-1651.

Lambert, D. (2008), Supply Chain Management: Processes, Partnerships, Performance, Supply Chain Management Institute, Sarasota, FL. 
Lehoux, N., D’Amours, S. and Langevin, A. (2011), Methodology for Assessing Collaboration Strategies and Incentives in the Pulp and Paper Industry, in Supply Chain Coordination under Uncertainty, Springer, Berlin, Heidelberg, pp. 625-650.

Liu, Y., Huang, Y., Luo, Y. and Zhao, Y. (2012), "How does justice matter in achieving buyersupplier relationship performance?” Journal of Operations Management, Vol. 30 No. 5, pp. 355367.

Mahajan, J., Radas, S. and Vakharia, A. J. (2002), “Channel strategies and stocking policies in uncapacitated and capacitated supply chains”, Decision Sciences, Vol. 33 No. 2, pp. 191-222.

Mayer, R. C., Davis, J. H. and Schoorman, F. D. (1995), “An integrative model of organizational trust”, Academy of Management Review, Vol. 20 No. 3, pp. 709-734.

Michalski, M., Afifi, R., Montes, J. L. and Fischer, B. D. (2013), “Asymmetries in supply chain management: Differences between Poland and Spain”, Journal of Management Policy and Practice, Vol. 14 No. 6, pp. 42-72.

Mishra, S. (2014), “A Pittsburgh-based software consultant and VendorManagedInventory.com contributor on a trade journal”, available at: http://www.datalliance.com/TED_VMI_article.pdf (accessed 03 July 2014).

Niranjan, T. T., Wagner, S. M. and Thakur-Weigold, B. (2011), “Are you ready for VMI?”, Industrial Engineer, Vol. 43 No. 2, pp. 39-44.

Özer, Ö., Zheng, Y. and Chen, K. Y. (2011), “Trust in forecast information sharing”, Management Science, Vol. 57 No. 6, pp. 1111-1137.

Özpolat, K. and Dresner, M. (2018), "A Dark Side of Long-term VMI Relationships: Supply Chain Trust", Research in Logistics and Production, Vol.8, No. 2, pp. 117-143.

Perona, M., and Saccani, N. (2004), "Integration techniques in customer-supplier relationships: An empirical research in the Italian industry of household appliances", International Journal of Production Economics, Vol. 89 No. 2, pp. 189-205.

Podsakoff, P. M., MacKenzie, S. B., Lee, J. Y. and Podsakoff, N. P. (2003), "Common method biases in behavioral research: a critical review of the literature and recommended remedies", Journal of Applied Psychology, Vol. 88 No. 5, pp. 879-903.

Radzuan, K., Rahim, M. K. I. A., Anuar, H. S., Nawi, M. N. M. and Osman, W. N. (2015), "Inventory management practices and its effects on vendor managed inventory performance", Advanced Science Letters, Vol. 21 No. 6, pp. 2114-2117.

Reitner, K., Wetzlinger, W. and Ortner, W. (2012), “A process framework for implementing VMI on the demand side”, Research in Logistics \& Production, Vol. 2, pp. 31-42. 
Sahin, F. and Robinson, E. P. (2002), "Flow coordination and information sharing in supply chains: review, implications, and directions for future research”, Decision Sciences, Vol. 33 No. 4, pp. 505-536.

Torres, F., Garcia-Diaz, C. and Rakoto-Ravalontsalama, N. (2014), “An evolutionary game theory approach to modeling VMI policies”, IFAC Proceedings Volumes, Vol. 47 No. 3, pp. 1073710742.

Vakharia, A. J. (2002), "E-business and supply chain management”, Decision Sciences, Vol. 33 No. 4, pp. 495-504.

Vigtil, A. (2007), "Information exchange in vendor managed inventory”, International Journal of Physical Distribution \& Logistics Management, Vol. 37 No. 2, pp. 131-147.

Villena, V. H., Revilla, E. and Choi, T. Y. (2011), "The dark side of buyer-supplier relationships: A social capital perspective”, Journal of Operations Management, Vol. 29 No. 6, pp. 561-576.

Waller, M., Johnson, M. E. and Davis, T. (1999), "Vendor-managed inventory in the retail supply chain”, Journal of Business Logistics, Vol. 20 No. 1, pp. 183-203.

Wells, C. V. and Kipnis, D. (2001), "Trust, dependency, and control in the contemporary organization”, Journal of Business and Psychology, Vol. 15 No. 4, pp. 593-603.

Whipple, J. M. and Russell, D. (2007), "Building supply chain collaboration: a typology of collaborative approaches”, International Journal of Logistics Management, Vol. 18 No. 2, pp. 174 $-196$

Williamson, O. E. (2002), "The theory of the firm as governance structure: from choice to contract”, The Journal of Economic Perspectives, Vol. 16 No. 3, pp. 171-195.

Xu, K., Yin, R. and Dong, Y. (2016), "Stockout recovery under consignment: The role of inventory ownership in supply chains”, Decision Sciences, Vol. 47 No. 1, pp. 94-124.

Yao, Y., Dong, Y. and Dresner, M. (2012), "Supply chain learning and spillovers in vendor managed inventory”, Decision Sciences, Vol. 43 No. 6, pp. 979-1001.

Yao, Y., Evers, P. T. and Dresner, M. E. (2007), "Supply chain integration in vendor- managed inventory”, Decision Support Systems, Vol. 43 No. 2, pp. 663-674.

Yu, H., Zeng, A. Z. and Zhao, L. (2009), "Analyzing the evolutionary stability of the vendormanaged inventory supply chains”, Computers \& Industrial Engineering, Vol. 56 No. 1, pp. 274282. 
Table Ia. Industry frequency in sample

\begin{tabular}{lll}
\hline Industry & Frequency & Percent \\
\hline Electrical & 26 & 48 \\
Auto & 19 & 35 \\
Others & 9 & 17 \\
Total & 54 & 100 \\
\hline
\end{tabular}

Table Ib. Distributor size in sample

\begin{tabular}{lc}
\hline $\begin{array}{l}\text { Total Number } \\
\text { of Employees }\end{array}$ & $\begin{array}{l}\text { Distributor } \\
\text { Count }\end{array}$ \\
\hline 50 or fewer & 7 \\
51 to 200 & 20 \\
201 to 500 & 18 \\
501 to 1000 & 3 \\
1001 or more & 7 \\
\hline
\end{tabular}

Table IIa. Descriptive statistics

\begin{tabular}{|c|c|c|c|c|c|c|c|c|}
\hline Variable* & \multicolumn{2}{|c|}{ Mean } & SD & Min & Max & Skewnes & \multicolumn{2}{|c|}{ Kurtosis } \\
\hline Dependence & \multicolumn{2}{|c|}{3.26} & 0.46 & 2 & 4.5 & 0.04 & \multicolumn{2}{|c|}{3.80} \\
\hline Trust & \multicolumn{2}{|c|}{4.09} & 0.46 & 2.5 & 5.0 & -0.75 & \multicolumn{2}{|c|}{5.06} \\
\hline Ptt & \multicolumn{2}{|c|}{3.18} & 0.52 & 2.0 & 4.0 & -0.07 & \multicolumn{2}{|c|}{2.11} \\
\hline Size & \multicolumn{2}{|c|}{3.61} & 1.02 & 1.5 & 5.0 & -0.46 & \multicolumn{2}{|c|}{2.14} \\
\hline Length of VMI & \multicolumn{2}{|c|}{3.91} & 2.56 & 0.5 & 8.0 & 0.29 & \multicolumn{2}{|c|}{1.96} \\
\hline Length of Relation & \multicolumn{2}{|c|}{6.82} & 2.19 & 0.5 & 8.0 & -1.57 & \multicolumn{2}{|c|}{4.03} \\
\hline Industry VMI Use & \multicolumn{2}{|c|}{19.2} & 14.12 & 10 & 70 & 1.61 & \multicolumn{2}{|c|}{5.15} \\
\hline Performance & \multicolumn{2}{|c|}{3.62} & 0.72 & 2 & 5 & -0.65 & \multicolumn{2}{|c|}{3.03} \\
\hline Factors of Trust & Mean & sd & & Factor & of Dep & ndence & Mean & sd \\
\hline Fairness & 4.25 & 0.62 & & $\%$ of $\mathrm{pl}$ & rchases & & 2.06 & 1.12 \\
\hline Unfair advantage & 2.30 & 0.92 & & $\%$ of $\mathrm{V}$ & MI prod & & 3.38 & 1.18 \\
\hline Welfare & 3.76 & 0.69 & & Supplie & import & nce & 4.50 & 0.80 \\
\hline Keeping promises & 4.05 & 0.68 & & Other s & ippliers & & 3.02 & 1.04 \\
\hline Ability - competence & 4.27 & 0.53 & & & & & & \\
\hline Trustworthy reputation & 4.33 & 0.61 & & & & & & \\
\hline
\end{tabular}

*Mean values are average of all items/measures for a dimension/factor/variable. 
Table IIb. Correlation matrix

\begin{tabular}{llllllllll}
\hline & & $\mathbf{1}$ & $\mathbf{2}$ & $\mathbf{3}$ & $\mathbf{4}$ & $\mathbf{5}$ & $\mathbf{6}$ & $\mathbf{7}$ & $\mathbf{8}$ \\
\hline $\mathbf{1}$ & Dependence - 4 items & 1 & & & & & & & \\
$\mathbf{2}$ & Trust - 6 items & -0.018 & 1 & & & & & & \\
$\mathbf{3}$ & Ptt - 3 items & -0.047 & 0.429 & 1 & & & & & \\
$\mathbf{4}$ & Size - 2 items & 0.156 & 0.232 & 0.217 & 1 & & & & \\
$\mathbf{5}$ & Length of VMI & 0.304 & -0.327 & -0.238 & 0.160 & 1 & & & \\
$\mathbf{6}$ & Length of Relation & 0.148 & -0.290 & -0.103 & 0.224 & 0.321 & 1 & & \\
$\mathbf{7}$ & Industry VMI Use & 0.378 & -0.030 & -0.034 & 0.006 & 0.114 & 0.126 & 1 & \\
$\mathbf{8}$ & Performance & 0.252 & 0.220 & 0.021 & 0.371 & 0.127 & 0.005 & -0.032 & 1 \\
\hline
\end{tabular}

Table III. OLS regression results

\begin{tabular}{|c|c|c|c|}
\hline$\underline{\text { Variables }}$ & $\begin{array}{l}\text { Model-1 } \\
\text { DV: Dependence } \\
\end{array}$ & $\begin{array}{l}\text { Model-2 } \\
\text { DV: Trust }\end{array}$ & $\begin{array}{l}\text { Model-3 } \\
\text { DV: Trust }\end{array}$ \\
\hline Length of VMI & $0.17^{*}$ & - & - \\
\hline Length of Relation & - & $-0.41^{* *}$ & $-0.41 * *$ \\
\hline Size & -0.13 & 0.19 & 0.21 \\
\hline Dependence & - & -0.03 & $2.85^{*}$ \\
\hline Dependence $^{2}$ & - & - & $-0.11 *$ \\
\hline Propensity to Trust & - & $0.67 * * *$ & $0.67^{* * *}$ \\
\hline Industry Auto & -0.54 & -1.10 & -1.07 \\
\hline Industry Electrical & 0.57 & -1.06 & -1.13 \\
\hline Industry VMI Use & $0.04^{* * *}$ & 0.18 & 0.01 \\
\hline Performance & $0.20 *$ & 0.01 & 0.14 \\
\hline $\mathrm{R}^{2}$ & $31 \%$ & $33 \%$ & $38 \%$ \\
\hline Adj. $R^{2}$ & $22 \%$ & $22 \%$ & $25 \%$ \\
\hline \# observations & 54 & 54 & 54 \\
\hline
\end{tabular}


Table IV. Survey questionnaire

Questions and Constructs

(Unless otherwise noted: measured via five-point Likert-type scale, 1 = strongly disagree, 2 = disagree, 3 = neutral, $4=$ agree, $5=$ strongly agree)

\section{Trust}

We receive fair treatment from this supplier.

If given a chance, this supplier could take unfair advantage in our business relationship.

When making important decisions, this supplier considers our firm's welfare as well as its own.

Based on past experience, we can rely on this supplier to keep promises made to our firm.

This supplier is competent and capable of providing us with required products according to our specifications in a timely fashion.

This supplier has a reputation for trustworthiness in the business world.

\section{Dependence}

This supplier is important to our firm.

Approximately, ___ _ percent of our purchases (dollar value) is from this supplier:

(five-point Likert-type scale, 1 = less than $5 \%, 2=5 \%$ to $15 \%, 3=16 \%$ to $30 \%, 4=31 \%$ to $50 \%, 5=$ more than $50 \%$ )

The replenishment of __ percent of the products purchased from this supplier is done through VMI.

(five-point Likert-type scale, 1 = less than $25 \%, 2=25 \%$ to $50 \%, 3=51 \%$ to $75 \%, 4=76 \%$ to $99 \%, 5=100 \%$ )

Approximately how many other suppliers are available in the supply market for the product(s) you purchase from this supplier?

(five-point Likert-type scale, 1 = none, $2=1$ to $2,3=3$ to $5,4=6$ to $10,5=$ more than 10 )

\section{Performance}

Use of VMI has improved our fill rate to our customers.

Use of VMI has allowed us to reduce our inventory related costs.

Use of VMI has increased our inventory turnover.

\section{Propensity to Trust (PTT)}

Most business partners can be counted on to do what they say they will do.

These days, our business should be alert; otherwise some other firms are likely to take advantage of us.

In dealing with our suppliers and customers, each and every aspect of the relationship should be written in a contract to prevent opportunistic behavior.

\section{Literature}

Dyer and Chu 2000

Dyer and Chu 2000

Doney and Cannon 1997

Zaheer et al 1998

Dyer\&Chu 2000

Chwelos et al 2001

Chwelos et al 200

Chwelos et al 2001

Mayer and Davis 1999 


\section{Length of Relationships}

(five-point Likert-type scale, 1 = less than a year, 2 = 1-2 years, 3 = 3-4 years, 4 = 5-6 years, 5 = 7 years or more)

How long has your firm been doing business with this supplier? (Round to the nearest year)

How long have you been personally involved in your firm's relationship with this supplier?(Round to the nearest year)

How long has your firm been using VMI with this supplier? (Round to the nearest year)

\section{Size}

How many employees does your firm have (all locations)?

(five-point Likert-type scale, 1 = 50 or fewer, $2=51$ to 200, $3=201$ to 500, $4=501$ to 1000, $5=1001$ or more)

Please indicate the total revenues for your firm (all locations) in 2010 (or fiscal year 2010) by selecting the appropriate number below.

(five-point Likert-type scale, $1=$ less than $\$ 1$ million, $2=\$ 1$ to $\$ 4.99$ million, $3=\$ 5$ to $\$ 19.99$ million, $4=\$ 20$ to $\$ 50$ million, $5=$ more than $\$ 50$ million)

\section{Industry}

In what industry does your firm mainly operate? Please circle the appropriate option or, write the industry next to the

"Other" choice. ( 1 = Electrical, 2 = Plumbing, 3 = Auto Parts, 4 = Health Care, 5 = Consumer Goods, $6=$ Other $)$

Approximately what percentage of firms in your industry uses a VMI arrangement with their suppliers?

(five-point Likert-type scale, 1 = less than $20 \%, 2=20 \%$ to $40 \%, 3=41 \%$ to $60 \%, 4=61 \%$ to $80 \%, 5=81 \%$ to $100 \%$ ) 
Figure 1. (a) Linear relation between dependence and length of VMI, and (b) Curvilinear relation between dependence and trust

(a)

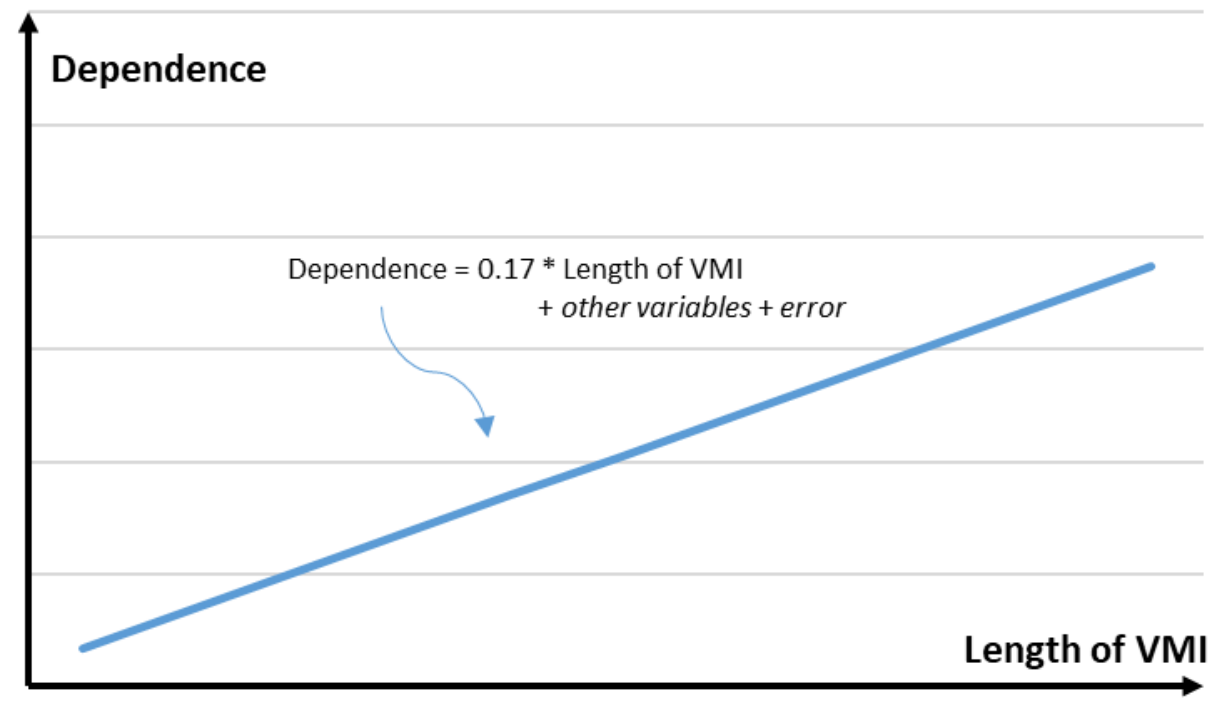

(b)

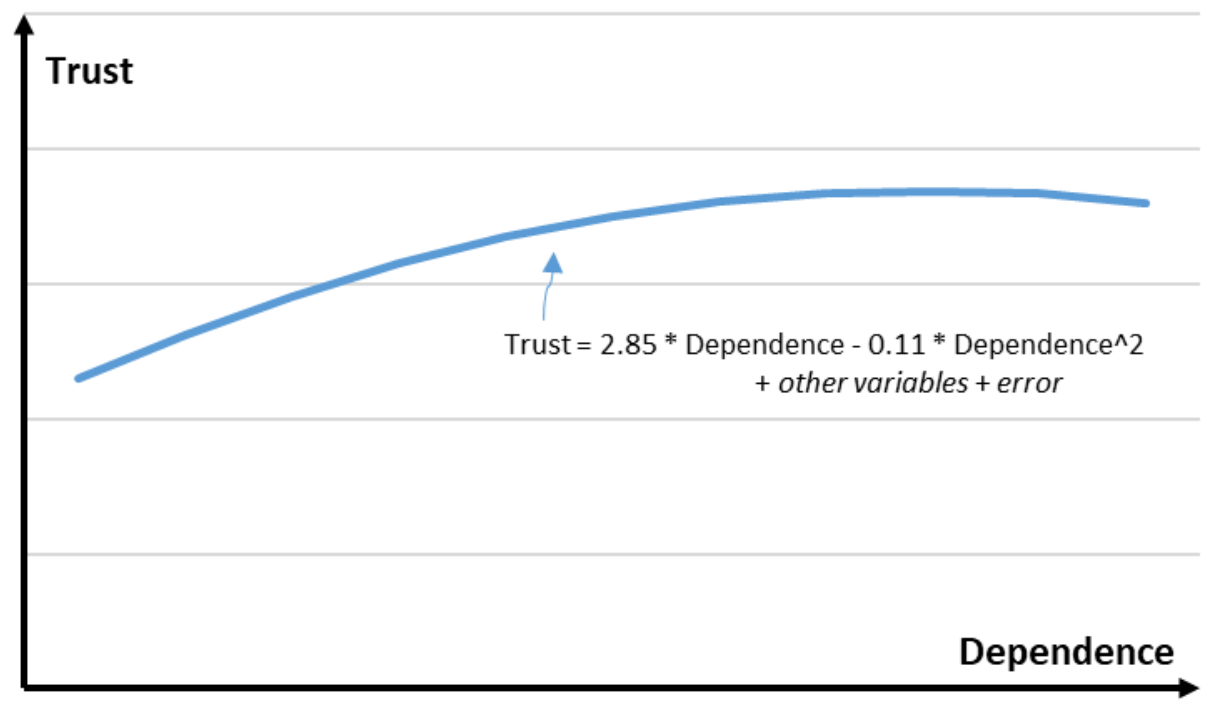

